\title{
A RESEARCH ON INTERACTION BETWEEN BITCOIN AND FOREIGN EXCHANGE RATES
}

\section{DOI: 10.17261/Pressacademia.2019.1028}

JEFA- V.6-ISS.1-2019(5)-p.55-62

\section{Mustafa Ozyesil}

Istanbul Aydin University, Istanbul, Turkey.

mozyesil@aydin.edu.tr, ORCID: 0000-0002-4442-7087

Date Received: December 24, 2018

Date Accepted: March 22, 2019

To cite this document

Ozyesil, M. (2019). A research on interaction between bitcion and foreign exchange rates. Journal of Economics, Finance and Accounting (JEFA), V.6(1), p.55-62.

Permemant link to this document: http://doi.org/10.17261/Pressacademia.2019.1028

Copyright: Published by PressAcademia and limited licenced re-use rights only.

\begin{abstract}
Purpose - This study conducts an analysis to reveal the interaction between Bitcoin and Exchange Rates to find out whether Bitcoin is becoming a substitution for the exchange rates.

Methodology - To investigate the mutually interaction between the exchange rates and the Bitcoin, the interaction (relationship) between daily closing price of both exchange rates and Bitcoin was analyzed through the Var model. Thus, it was tried to show the sensitivity of the values of Bitcoin to the changes occured in the exchange rates.

Findings - Based on Variance Decomposition analysis, BITCOIN and Euro can be considered as largely external variables and their prices are not significantly affected by USD. An interesting result in this study is that the USD exchange rate was found to be significantly sensitive to the Euro.

Conclusion - Findings obtained from analysis show that Bitcoin and Excange Rates have not become an alternative tools for each other yet.

Keywords: Cryptocurrencies, bitcoin, variance decomposition, Var model, unit root test.

JEL Codes: C23, C58, G10, G32
\end{abstract}

\section{INTRODUCTION}

Bitcoin mostly called as digital money is a kind of platform that enables for using virtual money by electronic payment. Since 2009 when anonymous people under the Nakamoto nickname developed it, Bitcoin has been used for around 2.5 million transactions between 109 million accounts (Böhme and Christin, 2015:213). As of March 2019, its market value is approiximately 71 Billion USD. Bitcoin is simply a type of electronic money which is subject to transfer from one economic unit to another and is confirmed by a remaining balance that the owner of the currency holds (Dwyer, 2015:81).

As a crypto currency Bitcoin is differing from conventional money term based on these properties as follows (Çarkacıoğlu, 2016:15-16):

- The Bitcoin network is not centralized namely cannot be managed by a center. Therefore no supervisory institution exists. It consists of a network based on an end-to-end interconnected computers.

- While in other types of digital currency, users need a trusted agent Bitcoin does not need the broker and trust.

- Bitcoin does not mean the debt, it can be defined as the value carrier. However, money in bank deposit accounts is a type of debt and represents the debt of a bank to its client.

- No permission required. No one can interfere in the system.

- The system is safe. Security is ensured by using mathematically proven cryptographic digital signing methods.

- İşlemler geri alınamaz.

- No authority includes even government and system developer cannot change or take back a transaction that is made by a miner and accepted by the others and recorded to Block Chain.

- Transactions are transparent, fast and global. Transactions are anonymous. Transactions are not related to real persons, organizations and bank accounts. There is no influence of banks and states on bitcoin supply. No external money supply can be made to the system therefore, inflation issue does not occur. 
What the makes Bitcoin most popular is its price movement it other words its fluctutations. Bitcoin is the first cryptocurrency and take majority of the attention made for cryptocurrencies. Because it is considered as cryptocurrency that has the potential to disrupt conventional payment methods and finally resulted in affecting all financial system (Böhme and Christin, 2015:214). Therefore, in this study, we aimed to assess that whether Bitcoin is becoming an alternative for the exchange rates.

\section{DATA AND METHODOLOGY}

\subsection{Sample Construction}

In this study as cryptocurrency Bitcoin (BIT) and as exchange rates USD and EUR were used. The study was carried out with daily data of 27.10.2017-25.02.2019. The days of the data have been synchronized by us. Natural logarithms of all series were used in the analysis. By taking the natural logarithms of the data, the risk of heteroscedasticity problem has been reduced and the opportunity of the interpret of the results (evident) as flexibility coefficient have been obtained. The data is obtained from www.investing.com.

\subsection{Model}

In this study, the stationary of the series were analyzed with ADF (Augmented Dickey Fuller) and PP (Phillips Perron) unit root tests. Interactions between the series were analyzed by the Impulse-Response Function and Variance Decomposition methods based on the VAR (Vector Aotoregressive) method.

\section{FINDINGS AND DISCUSSIONS}

\subsection{Unit Root Test}

In econometric analyzes, determining the stationary degrees of the series and carrying out the subsequent analyzes in the light of this information has vital importance for the analysis to produce reliable results.(Cochrane, 1991). Stationarity of series can be determined by unit root tests. In the study, the stationary level of the series was tested with ADF and PP methods. Among these tests, ADF is preferred for being the most widely used test while PP is preferred because it is accepted stronger than ADF (Arltova ve Fedorová, 2016) in the analysis which includes trend.

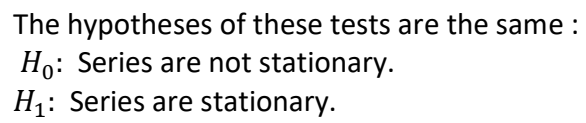

As a result of these tests, series which become stationary without taking their first difference are called as $I(0)$ and other series which become stationary after taking their first differences are called as I(1) (Dikmen, 2012: 304). In this study, ADF and PP unit root tests were performed and the results are presented in Table 1.

Table 1: Unit Root Test Results

\begin{tabular}{|c|c|c|c|c|c|}
\hline \multirow[b]{2}{*}{ Variable } & \multicolumn{2}{|c|}{ Origin Level } & \multicolumn{2}{|c|}{ First Difference } & \multirow[b]{2}{*}{ Decision } \\
\hline & $\begin{array}{c}\text { Probability Value } \\
\text { of the ADF Test }\end{array}$ & $\begin{array}{c}\text { Probability Value } \\
\text { of the PP Test }\end{array}$ & $\begin{array}{c}\text { Probability Value } \\
\text { of the ADF Test }\end{array}$ & $\begin{array}{c}\text { Probability Value } \\
\text { of the PP Test }\end{array}$ & \\
\hline LnBIT & 0.48 & 0.42 & $0.00 * * *$ & $0.00 * * *$ & $I(1)$ \\
\hline LnUSD & 0.90 & 0.87 & $0.00 * * *$ & $0.00 * * *$ & $I(1)$ \\
\hline LnEUR & 0.91 & 0.90 & $0.00 * * *$ & $0.00 * * *$ & I(1) \\
\hline
\end{tabular}

Note: The optimum lag length in the ADF test is determined according to the Akaike Criterion and the optimum bandwidth in the PP test is determined according to the Newey-West method. Since the PP test is considered to be more robust, the decision is finalized based on the results of the PP test when different results are produced by the ADF and PP test methods. ${ }^{* * *}$ and ${ }^{*}$ state that the related series is stationary at $1 \%$ and $10 \%$ significance level, respectively. The unit root tests were not performed for the series which were stationary in the origin level values.

\subsection{VAR Analysis}

The VAR analysis developed by Sims (1980) was preferred in this study because it allows to analyze the interactions between variables simultaneously (Trenca and Mutu, 2011: 33-37). The relationships between factors that move simultaneously especially like monetary theory and financial instruments can be analyzed effectively by the VAR method (Triacca, 2017). In order to analyze the relations between two variables such as $Y$ and $X$ by VAR method, the following simultaneous equation system is used:

$$
Y_{t}=\alpha_{0}+\sum_{i=1}^{m} \alpha_{i} Y_{t-i}+\sum_{i=1}^{m} \beta_{i} X_{t-i}+u_{t}
$$




$$
X_{t}=\gamma_{0}+\sum_{i=1}^{m} \gamma_{i} X_{t-i}+\sum_{i=1}^{m} \varphi_{i} Y_{t-i}+\vartheta_{t}
$$

Here, $m$ denotes the optimal delay length. In this study, VAR estimates were made for Analysis 1 and Analysis 2 separately. In the VAR analysis, the optimal delay length was determined first, and the results of this transaction are presented in Appendix 1. In the VAR analysis, the findings are not directly interpreted and interpretations are made based on the results of Impact-Response Functions and Variance Decomposition.

\subsubsection{Impact-Response Functions}

This analysis examines the responses of variables located in the VAR model to their own or other variables' shocks. A standard-error shock occurred in one of the variables is examined by the response of the series itself and other variables (Rossi, 2011). In the study, generalized shocks are given while creating effect-response functions. The results are presented below: The order of the graphs indicates: In the first graph in each group, it is decided a variable is giving a response to the shock coming to it and thus it is decided whether this shock creates decreasing or increasing effect. In the other graphs, the responses of the other variables to the shocks that come from the first variable are monitored.

Chart 1: The Reaction of Exchange Rates to a Reducing Shock in BITCOIN's Price

Res ponse to Generalized One S.D. Innov ations \pm 2 S.E.

Response of DLNBIT to DLNBIT

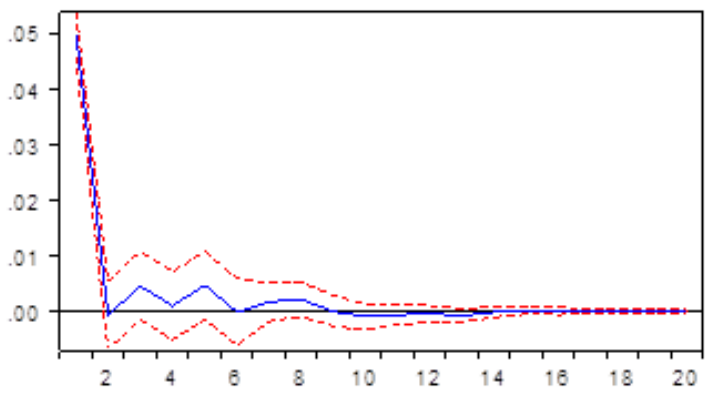

R esponse of D LNEU R to D LNBIT

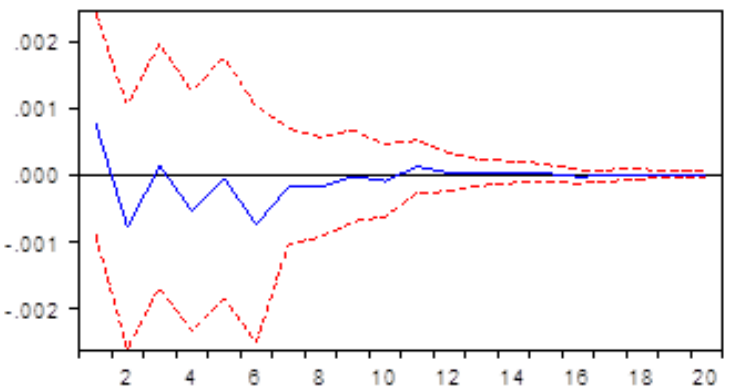

Response of DLN USD to DLN BIT

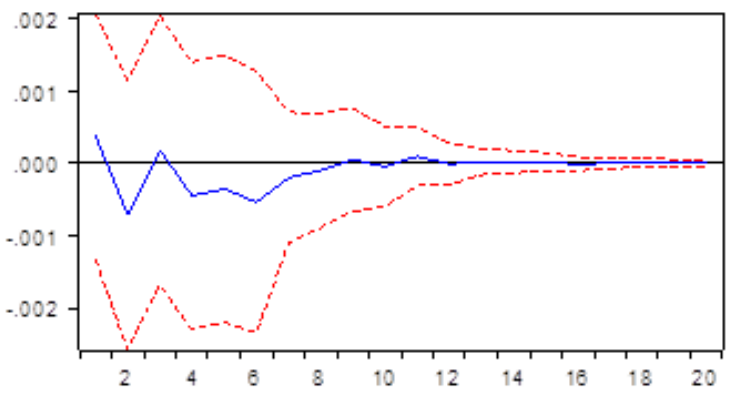

According to these graphs, it can be found that Euro and USD respond in reducing way to reducing shock occurred in Bitcoin's Prices. Therefore we can not conclude that Bitcoin and USD and Euro are substitution investment tools. Shocks have lost their effect on average in 12 days. 


\section{Chart 2: The Reaction of USD and Bitcoin to a Reducing Shock in Euro's Price}

Response of DLNEUR to DLNEUR

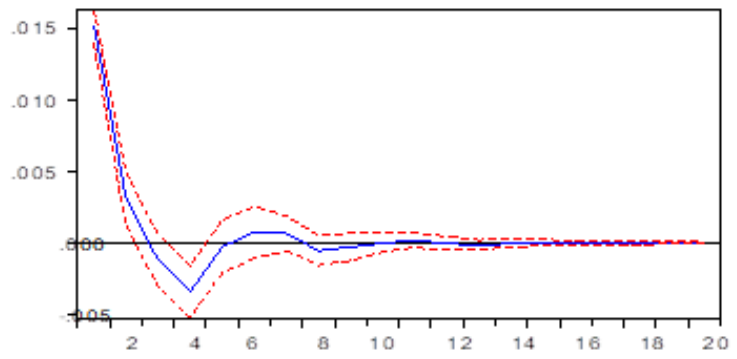

Response to Generalized One S.D. Innov ations \pm 2 S.E.

Response of DLNBIT to DLNEUR

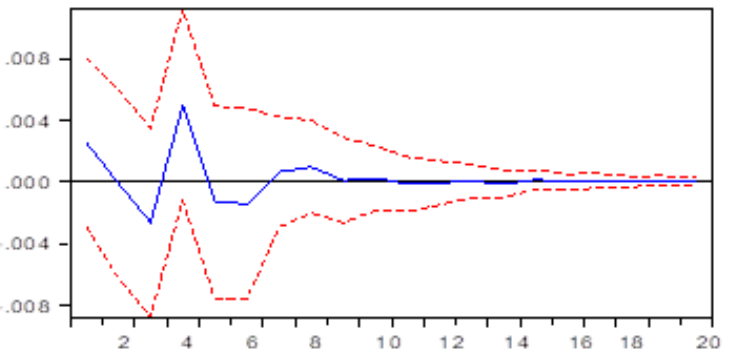

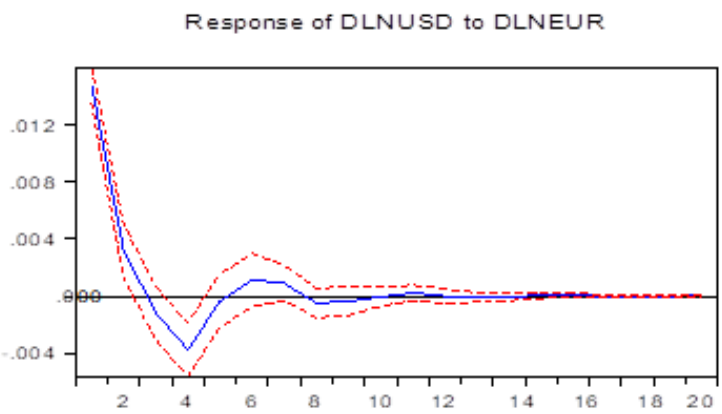

According to these graphs, it can be found that BITCOIN and USD respond in reducing way to reducing shock occurred in Euro's Prices. In this case, Euro, USD and Bitcoin cannot be expressed as substitution tools. Shocks have lost their effect on average in 14 days.

\section{Chart 3: The Reaction of Euro and Bitcoin to a Reducing Shock in USD's Price}

Response to Generalized One S.D. Innov ations \pm 2 S.E

Response of DLNUSD to DLNUSD Response of DLNBIT to DLNUSD
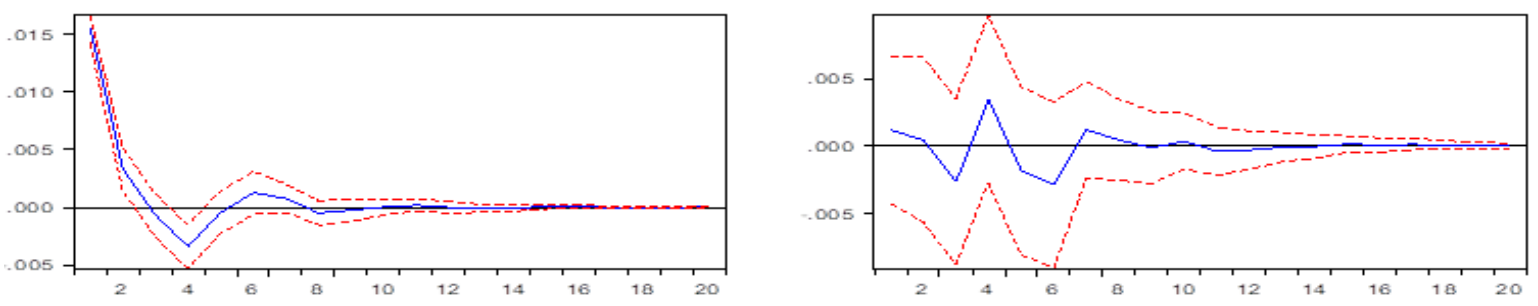

Response of DLNEUR to DLNUSD

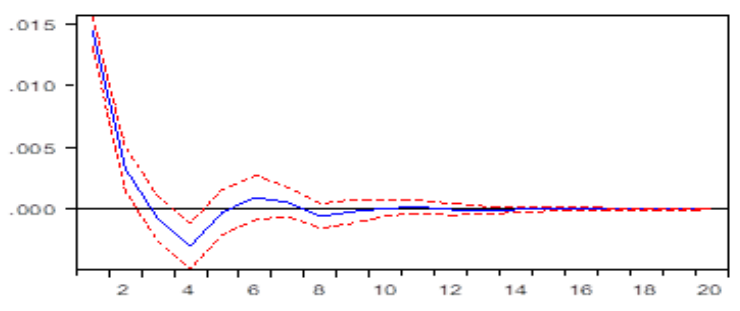


According to these graphs, it can be found that BITCOIN and Euro respond in reducing way to reducing shock occurred in USD 's Prices. In this case, USD, Bitcoin and Euro cannot be expressed as substitution currencies. Shocks have lost their effect on average in 10 days.

When the results obtained from the impact-response functions are evaluated together, it is difficult to say that exchange rates as USD and EUR and crypto money as Bitcoin cannot be regarded as alternative investment tool for each other.

\subsubsection{Variance Decomposition}

Variance decomposition method is used to determine how much of the change in each variable arises from changes in other variables and arises from itself (Tarl, 2012: 469). In the variance decomposition, the values in the first period in which the distribution reaches equilibrium are interpreted. In this study, variance decomposition was made for each variable separately and the findings are presented in the tables below. The variable which is tried to be explained in each table is made bold and the data shows how much of the changes in this variable are caused by itself. Other columns refer to the effects of changes in other variables in the analysis on the variable to be explained.

Table 2: Results of Variance Decomposition for Determining the Causes of Changes in BITCOIN

\begin{tabular}{cccc}
\hline \hline Period & DLNBIT & DLNEUR & DLNUSD \\
\hline \hline 1 & 100 & 0 & 0 \\
2 & 90.67 & 0.00 & 0.03 \\
3 & 88.65 & 0.36 & 0.03 \\
4 & 83.69 & 1.16 & 0.80 \\
5 & 82.20 & 1.19 & 0.81 \\
6 & 80.72 & 1.23 & 1.73 \\
7 & 80.18 & 1.23 & 1.90 \\
8 & $\mathbf{7 9 . 9 6}$ & 1.25 & 1.94 \\
9 & 79.27 & 1.24 & 1.93 \\
\hline \hline
\end{tabular}

According to Table 2, after 8th period, in the distribution, equilibrium was established. In this case, $79.96 \%$ of the changes in BITCOIN were caused by itself, $1.25 \%$ from Euro and $1.94 \%$ from USD. The reasons why the effects of the USD are higher than Euro's are USD's intensity of use (trade volume) in financial transactions worldwide and Bitcoin is being charged in terms of USD dollars.

Table 3: Results of Variance Decomposition for Determining the Causes of Changes in Euro

\begin{tabular}{cccc}
\hline \hline Period & DLNBIT & DLNEUR & DLNUSD \\
\hline \hline 1 & 0.26 & 99.42 & 0 \\
2 & 0.49 & 96.93 & 0.41 \\
3 & 0.49 & 95.43 & 1.00 \\
4 & 0.57 & 94.85 & 1.13 \\
5 & 0.57 & 93.76 & 1.13 \\
6 & $\mathbf{0 . 7 6}$ & $\mathbf{9 2 . 9 0}$ & $\mathbf{1 . 2 6}$ \\
7 & 0.77 & 92.44 & 1.28 \\
\hline \hline
\end{tabular}

According to Table 3, after 6th period, in the distribution, equilibrium was established. In this case, $92.90 \%$ of the changes in Euro were caused by itself, $1.88 \%$ from BITCOIN and $1.26 \%$ from USD. Here Euro is an external variable and the value of the Euro is not determined by the variables included in the analysis. 
Table 4: Results of Variance Decomposition for Determining the Causes of Changes in USD

\begin{tabular}{cccc}
\hline \hline Period & DLNBIT & DLNEUR & DLNUSD \\
\hline \hline 1 & 0.06 & 90.49 & 8.75 \\
2 & 0.25 & 88.82 & 8.45 \\
3 & 0.26 & 87.46 & 9.00 \\
4 & 0.32 & 87.60 & 8.57 \\
5 & 0.36 & 86.60 & 8.60 \\
6 & 0.45 & 85.96 & 8.59 \\
7 & $\mathbf{0 . 4 6}$ & $\mathbf{8 5 . 6 3}$ & $\mathbf{8 . 5 5}$ \\
8 & 0.47 & 85.61 & 8.55 \\
\hline \hline
\end{tabular}

According to Table 4, after 7th period, in the distribution, equilibrium was established. In this case, $8.55 \%$ of the changes in USD were caused by itself and $0.46 \%$ from BITCOIN and $85.63 \%$ from Euro. Here, the factors that best explain the changes in the USD are the changes in the Euro.

\section{CONCLUSION}

In this study, the interaction between the closing prices of the Bitcoin and the closing values of the exchange rates (USD and EUR) was analyzed using the daily data of 27.10.2017-25.0.2019 period. Since the data were daily and closely interrelated, simultaneous analysis methods such as the VAR method.

The series were examined by ADF and PP unit root tests and it was observed that all series were I(1). Since VAR analysis and Granger causality tests can be performed only via the stationary series then all series were analyzed by taking their first differences. According to the Impact-Response functions based on the VAR analysis, we cannot prove that Bitcoin, USD and EUR are alternative investment tool for each other.

According to the results of VAR analysis based on Variance Decomposition, BITCOIN and Euro are largely external variables and their prices are not significantly affected by USD. This evidence also shows that they haven't become alternative for each other yet. An interesting result in this study is that the USD exchange rate was found to be significantly sensitive to the Euro.

The causality relations between the series were examined by Granger (1969) method. However, in this study, the causality relationship between the variables could not be determined in line with the results of the VAR Analysis.

Based on the findings obtained from this study, it can be understood that there is no significant interactions between Bitcoin, USD and EUR. The result may be beneficial for investors to consider diversification their portfolios.

\section{REFERENCES}

Arltova, M., Fedorová, D. (2016). Selection of unit root test on the basis of length of the time series and value of AR(1) parameter. Statistika, 96(3), 47-64.

Böhme, R., Christin, N., Edelman, B., Moore T. (2015). Bitcoin: Economics, technology, and governance. Journal of Economic Perspectives, 29(2),213-238

Cochrane, J. H. (1991). A critique of the application of unit root tests. Journal of Economic Dynamics and Control, 15, 275-284.

Çarkacıoğlu, A. (2016). Kripto para - bitcoin. Research Report, Capital Market Board, Ankara.

Dikmen, N. (2012). Ekonometri temel kavramlar ve uygulamalar. 2. Baskı, Dora Yayınevi, Bursa.

Dwyer, G. P. (2015). The economics of bitcoin and similar private digital currencies. Journal of Financial Stability, 17(C), 81-91.

Granger, C. W. J. (1969). Investigating causal relations by econometric models and cross spectral methods. Econometrica, 37(3),424-438.

Rossi, E. (2011). Impulse response functions. http://economia.unipv.it/pagp/pagine_personali /erossi/dottorato_svar.pdf, [Access Date: 02.03.2019].

Sims, C. A. (1980). Macroeconomics and reality. Econometrica. 48, 1-48.

Tarı, R. (2012). Ekonometri. 8. Baskı. Kocaeli: Umuttepe Yayınları. 
Trenca, I., Mutu, S. (2011). Advantages and limitations of VAR models used in managing market risk in banks. Finance - Challenges of the Future, 13, 32-43.

Triacca, U. (2017). Vector autoregressive models. http://www.phdeconomics.sssup.it/ documents/Lesson17.pdf, [Access Date: 02.03.2019]

\section{Appendix 1: Optimal Delay Length Determination Results}

VAR Lag Order Selection Criteria

Endogenous variables: DLNBIT DLNEUR DLNUSD

Exogenous variables: $\mathrm{C}$

Date: 03/01/19 Time: 11:44

Sample: 1334

Included observations: 325

\begin{tabular}{ccccccc}
\hline \hline Lag & LogL & LR & FPE & AIC & SC & HQ \\
\hline \hline 0 & 5853.323 & NA & $3.30 \mathrm{e}-26$ & -35.97122 & $-35.87808^{*}$ & $-35.93404^{*}$ \\
1 & 5920.588 & 130.8049 & $3.23 \mathrm{e}-26^{*}$ & $-35.99131^{*}$ & -35.15305 & -35.65676 \\
2 & 5981.355 & 115.1776 & $3.30 \mathrm{e}-26$ & -35.97142 & -34.38803 & -35.33949 \\
3 & 6040.707 & 109.5716 & $3.40 \mathrm{e}-26$ & -35.94281 & -33.61430 & -35.01350 \\
4 & 6106.917 & 118.9748 & $3.36 \mathrm{e}-26$ & -35.95641 & -32.88278 & -34.72972 \\
5 & 6159.995 & $92.76402^{*}$ & $3.62 \mathrm{e}-26$ & -35.88920 & -32.07045 & -34.36513 \\
6 & 6204.740 & 75.99782 & $4.10 \mathrm{e}-26$ & -35.77071 & -31.20683 & -33.94926 \\
7 & 6252.914 & 79.44922 & $4.57 \mathrm{e}-26$ & -35.67331 & -30.36432 & -33.55448 \\
8 & 6301.369 & 77.52818 & $5.11 \mathrm{e}-26$ & -35.57765 & -29.52353 & -33.16144 \\
\hline \hline
\end{tabular}

* indicates lag order selected by the criterion

LR: sequential modified LR test statistic (each test at $5 \%$ level)

FPE: Final prediction error

AIC: Akaike information criterion

SC: Schwarz information criterion

HQ: Hannan-Quinn information criterion

The optimum lag length is 1 according to FPE and AIC in this table. However, when the 1-delayed VAR model was estimated, an autocorrelation problem was detected in the model, and it was taken as an optimal delay length of 5 models determined according to the LR criteria. Autocorrelation test results for the 5-delayed VAR model:

VAR Residual Serial Correlation LM Tests

Date: 03/01/19 Time: 11:50

Sample: 1334

Included observations: 328

\begin{tabular}{ccccccc}
\hline \hline $\begin{array}{c}\text { Null hypothesis: No serial } \\
\text { correlation at lag } \mathrm{h}\end{array}$ & & & & & \\
\hline \hline & LRE* stat & df & Prob. & Rao F-stat & df & Prob. \\
\hline \hline 1 & 72.76184 & 64 & 0.2119 & 1.140601 & $(64,1575.4)$ & 0.2121 \\
2 & 74.69924 & 64 & 0.1696 & 1.171683 & $(64,1575.4)$ & 0.1698 \\
3 & 62.48444 & 64 & 0.5303 & 0.976344 & $(64,1575.4)$ & 0.5306 \\
4 & 71.51107 & 64 & 0.2426 & 1.120554 & $(64,1575.4)$ & 0.2428 \\
5 & 92.24804 & 64 & 0.0119 & 1.454936 & $(64,1575.4)$ & 0.0120 \\
\hline \hline
\end{tabular}

Null hypothesis: No serial correlation at lags 1 to $\mathrm{h}$ 


\begin{tabular}{ccccccc} 
Lag & LRE* stat & df & Prob. & Rao F-stat & df & Prob. \\
\hline \hline 1 & 72.76184 & 64 & 0.2119 & 1.140601 & $(64,1575.4)$ & 0.2121 \\
2 & 152.2228 & 128 & 0.0709 & 1.196820 & $(128,1916.4)$ & 0.0714 \\
3 & 217.3174 & 192 & 0.1015 & 1.138667 & $(192,1965.9)$ & 0.1029 \\
4 & 286.5945 & 256 & 0.0916 & 1.127037 & $(256,1946.0)$ & 0.0942 \\
5 & 364.0540 & 320 & 0.0452 & 1.148332 & $(320,1903.3)$ & 0.0479 \\
\hline \hline
\end{tabular}

*Edgeworth expansion corrected likelihood ratio statistic.

According to this table, there is no autocorrelation problem in the 5 - delayed VAR model. The graphic of inverse characteristic roots shows that the 5 - delayed VAR model is stable as follows :

Inverse Roots of AR Characteristic Polynomial

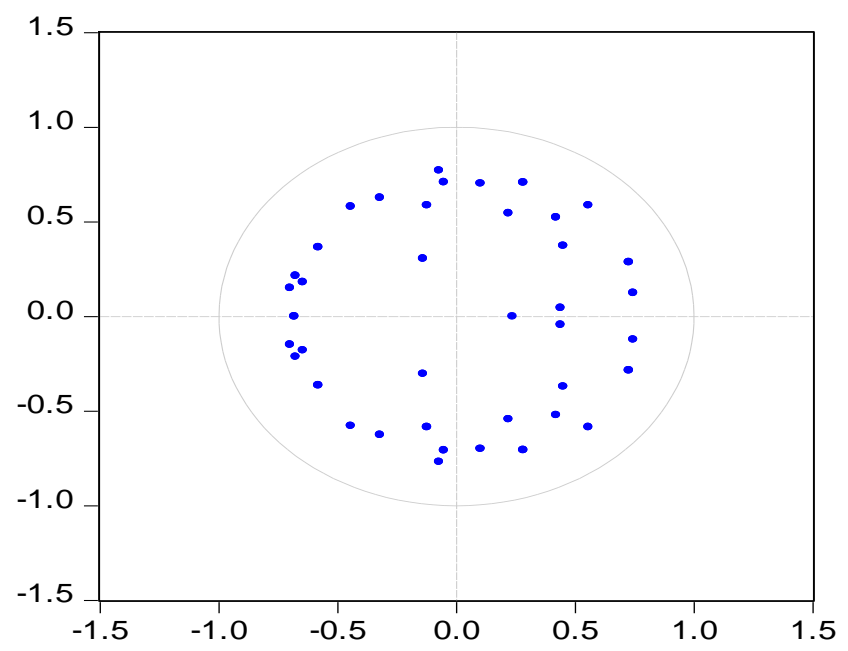

In this graph, it was decided that the 5 delayed VAR model was stable because the inverse characteristic polynomial roots remained within the unit circle. 